\title{
Correspondence \\ Methodological Weaknesses in Non-Randomized Studies of Ecstasy (MDMA) Use: A Cautionary Note to Readers and Reviewers
}

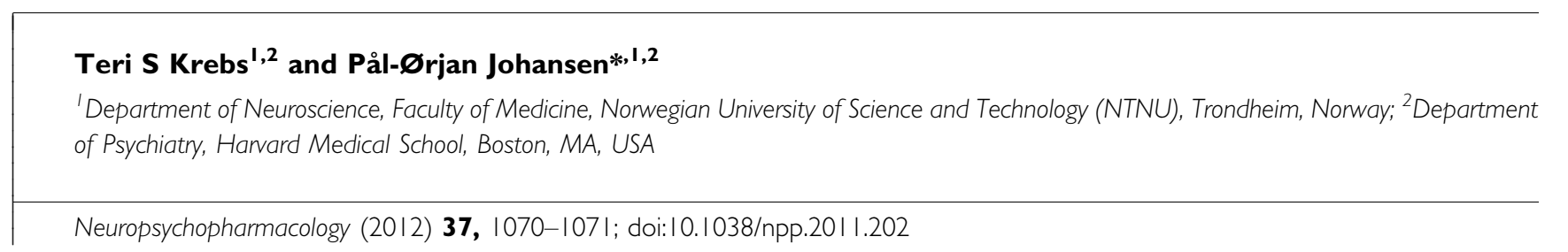

Authors of nonrandomized studies of people who have used ecstasy (an illicit drug typically consisting of (+/-)-3,4methylenedioxymethamphetamine, MDMA) often claim that any small difference between users and non-users is evidence of neurotoxic damage, while ignoring the possibility of pre-existing confounding factors (such as impulsivity or childhood adversity) that might mediate both increased drug use and physiological or neurocognitive differences (Krebs et al, 2009). The recent cross-sectional fMRI study of BOLD signal activation in response to visual stimuli by Bauernfeind et al (2011) is not an exception.

Bauernfeind et al report that increasing ecstasy use was correlated with increased cortical excitability, and they suggest that this is most likely related to the damage caused to serotonin transporters. In a press release, principal investigator RL Cowan compared the ecstasy users with people with early Alzheimer's disease (www.mc.vanderbilt. edu/news/releases.php?release $=2109$ ).

First, their data do not provide strong evidence for any effect at all, certainly not one indicating brain damage. The distribution (mean, median, range) of all cortical excitability measures is very similar among ecstasy users and non-users (Figure 1 shows the activation in the lateral geniculate nucleus (LGN)). Six of the seven findings reported in the abstract did not remain statistically significant after adjusting for the use of two different scanner and stimulus delivery methods, or for the use of multiple statistical tests-leaving only a correlation between extent of ecstasy use among ecstasy users (20 individuals, range $300-10000 \mathrm{mg}$ lifetime exposure, median $1750 \mathrm{mg}$ ), and increasing signal intensity in LGN. We reanalyzed the correlations using the complete data set (including 20 individuals with zero ecstasy use) and failed

*Correspondence: P- $\varnothing$ Johansen, Department of Neuroscience, Faculty of Medicine, Norwegian University of Science and Technology (NTNU), N-7489 Trondheim, Norway, Tel: + 4792293 108, E-mail: pal.johansen@ntnu.no

Received 21 June 20 I ; revised 27 July 20 I I; accepted 27 July 201 I to find significant correlations between the extent of ecstasy exposure and activation in the LGN (Spearman's $\rho-0.05$, $p=0.74)$, or any of the other four measures of cortical excitability ( $\rho$ range $0.07-0.26$; for all $p>0.10$ ).

Second, several studies have suggested an association between increased cortical activation in response to sensory stimuli and psychological factors such as impulsivity, depression, anxiety, and stress (eg, Röhl and Uppenkamp, 2010). All of these factors have also been suggested to predispose to repeated use of ecstasy. Indeed, an earlier study of ecstasy users and non-users found fMRI BOLD signal activation in response to a visual matching task was not correlated to ecstasy use after accounting for the correlation with impulsivity (Valdes et al, 2006). Note that, although Bauernfeind et al excluded people with psychiatric diagnoses, this is not sufficient to rule out the effect of

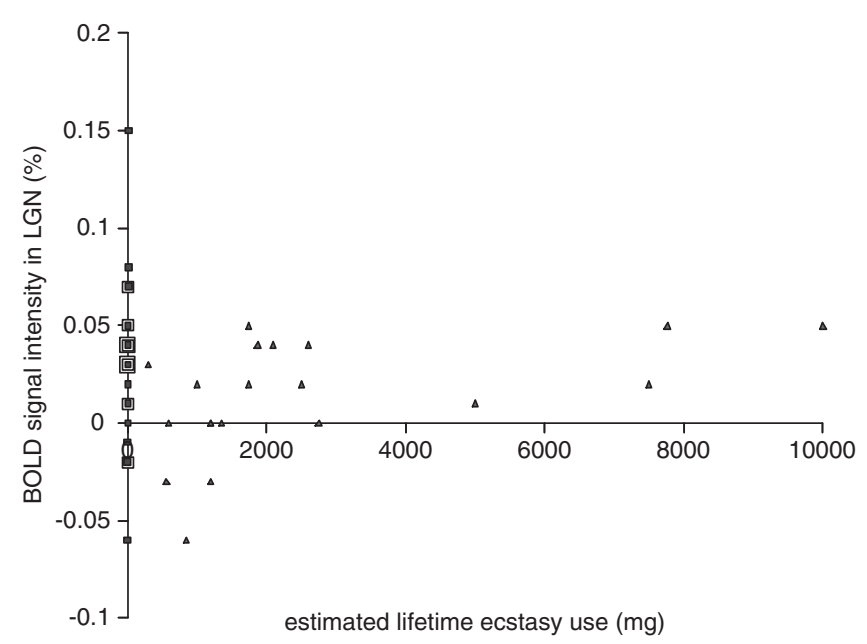

Figure I Signal intensity in the LGN in response to visual stimuli. Squares indicate individuals with no ecstasy use (median signal intensity $0.03 \%$, range $-0.06 \%$ to $0.15 \%$ ). Triangles indicate individuals who have used ecstasy (median signal intensity $0.02 \%$, range $-0.06 \%$ to $0.05 \%$ ). Outlines around the symbols indicate overlapping data points. 
personality traits, childhood experiences, and psychiatric symptoms.

Finally, the evidence of lower levels of serotonin transporter binding in people who have repeatedly used ecstasy also comes from small, non-randomized, retrospective studies that have not considered impulsivity and other potential pre-existing factors. In contrast, both published longitudinal studies found no decrease in serotonin transporter either in incident new users of ecstasy (de Win et al, 2008) or in heavy users, who continued to take ecstasy (Buchert et al, 2006).

\section{ACKNOWLEDGEMENTS}

This study was funded by the Research Council of Norway, grant number 185924.

\section{DISCLOSURE}

The authors declare no conflict of interest.

\section{REFERENCES}

Bauernfeind AL, Dietrich MS, Blackford JU, Charboneau EJ, Lillevig JG, Cannistraci CJ et al (2011). Human ecstasy use is associated with increased cortical excitability: an fMRI study. Neuropsychopharmacology 36: 1127-1141.

Buchert R, Thomasius R, Petersen K, Wilke F, Obrocki J, Nebeling $B$ et al (2006). Reversibility of ecstasy-induced reduction in serotonin transporter availability in polydrug ecstasy users. Eur J Nucl Med Mol Imaging 33: 188-199.

de Win MM, Jager G, Booij J, Reneman L, Schilt T, Lavini C et al (2008). Sustained effects of ecstasy on the human brain: a prospective neuroimaging study in novel users. Brain 131: 29362945.

Krebs TS, Johansen PØ, Jerome L, Halpern JH (2009). Importance of psychiatric confounding in non-randomized studies of heavy ecstasy users. Psychol Med 39: 876-878.

Röhl M, Uppenkamp S (2010). An auditory fMRI correlate of impulsivity. Psychiatry Res 181: 145-150.

Valdes IH, Steinberg JL, Narayana PA, Kramer LA, Dougherty DM, Swann AC et al (2006). Impulsivity and BOLD fMRI activation in MDMA users and healthy control subjects. Psychiatry Res 147: 239-242. 